\title{
Endobronchial ultrasound in the management of nonsmall cell lung cancer
}

\author{
Christophe Dooms*,\#, Inge Muylle ${ }^{\top}$, Jonas Yserbyt"*\# and Vincent Ninane
}

\begin{abstract}
Flexible bronchoscopy plays a major role in the diagnosis and staging of lung cancer. One of the most important advances in this field is the development of endobronchial ultrasound (EBUS), which has extended the view of the bronchoscopist. These techniques are safe and allow assessment of the depth of tumour invasion in the central airways, detection of peripheral tumours before sampling, localisation of the central tumour in the lung parenchyma close to the central airways for real-time guided sampling, and staging of lymph nodes within the mediastinum. Progress in handling and analyses of the small samples obtained during EBUS procedures also allow modern pathological and molecular studies to be performed. This article reviews the data currently available in the field of convex and radial probe EBUS for the diagnosis and staging of nonsmall cell lung cancer and highlights the strengths but also the weaknesses of these new techniques.
\end{abstract}

KEYWORDS: Endobronchial ultrasound, lung cancer, mediastinal lymphadenopathy, peripheral lung cancer, staging, transbronchial needle aspiration

ung cancer is the leading cancer killer in economically developed countries and nonsmall cell lung cancer (NSCLC) makes up about $80 \%$ of lung cancer cases. Flexible bronchoscopy plays a major role in the diagnosis and staging of lung cancer and the present article focuses on the utility of convex and radial probe endobronchial ultrasound (EBUS) in the diagnosis and staging of NSCLC.

\section{CONVEX AND RADIAL PROBE EBUS: TECHNICAL AND PRACTICAL PATHOLOGICAL ASPECTS}

A convex ultrasound transducer is located at the tip of a flexible scope and allows linear scanning parallel to the insertion direction of the flexible scope in order to assess structures around the central airways (fig. 1). This can be performed by direct contact of the probe with the airway wall or via a distal balloon inflated with water. The scope is connected to an ultrasound scanner with a colour Doppler system to better differentiate solid and vascular structures. A dedicated working channel allows the introduction of 21- or 22gauge needles for transbronchial needle aspiration (TBNA) under real-time guidance. Even if some ultrasound features might be predictive of lymph node malignancy, including round shape, distinct margin or heterogenous echogenicity $[1,2]$, no single echogenic aspect of a visualised lymph node can exclude sampling with TBNA. It is possible to visualise and sample lymph nodes with a short axis of $\geqslant 5 \mathrm{~mm}$ and the optimal number of aspirations per station has been reported to be about three [3]. When mediastinal nodal staging is required, systematic nodal sampling seems feasible [4], but some primary choices have to be made since it is often difficult to perform more than 6-8 aspirations per procedure under local anaesthesia with sedation. At least mediastinal nodal stations $4 \mathrm{R}, 4 \mathrm{~L}$ and 7 should be sought and sampled if the largest node measures $\geqslant 5 \mathrm{~mm}$. To avoid contamination problems, the order of sampling should begin at the

\section{AFFILIATIONS}

*Respiratory Division, University Hospitals Leuven, Leuven,

\#Dept of Clinical and Experimental Medicine, KU Leuven, Leuven, and

"Chest Service, Saint-Pierre University Hospital, Brussels, Belgium.

\section{CORRESPONDENCE}

V. Ninane

Chest Service

Saint-Pierre University Hospital

Rue Haute 322

1000 Brussels

Belgium

E-mail:

Vincent_ninane@stpierre-bru.be

Received:

March 042013

Accepted:

March 262013

PROVENANCE

Submitted article, peer reviewed. 


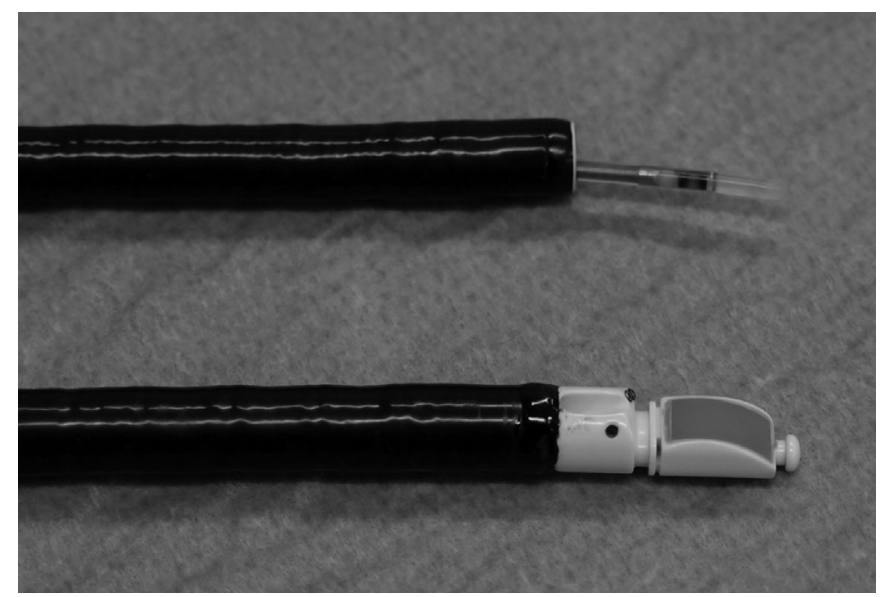

FIGURE 1. A convex ultrasound transducer is located at the tip of a dedicated bronchoscope for peribronchial linear scanning (bottom). A radial ultrasound transducer miniprobe is introduced through the biopsy channel of a standard bronchoscope for endobronchial scanning (top).

level of N3 nodes followed by N2 nodes and then the N1 nodes. If the tumour is located in close proximity to the central airways and pathology is required, sampling should be performed at the end of the procedure due to the risk of contamination. Rapid on site examination (ROSE) is a quick cytological examination that may shorten the procedural time, but data from meta-analysis show that ROSE is not associated with increased sensitivity [5,6]. Recent consensus from a panel of experts suggested that, rather than using ROSE, the largest possible number of aspirations should be performed in order to obtain as much material as possible to allow more biomarker testing [7]. Liquid-based cytology is becoming the preferred cytological specimen handling method since it allows the preparation of cell blocks for immunohistochemistry and molecular studies [7]. This is important since, in studies using convex probe EBUS as a staging procedure, a majority of the patients assessed will have as yet unproven lung cancers and lymph node samples will then often be the only material available [8]. The use of a 21-gauge needle does not increase the diagnostic yield in comparison with the 22-gauge needle [9], but the introduction of trans bronchial needle-forceps (EBUS-TBNF) may allow histological sampling from the lymph nodes to be obtained [10].

Subtyping and/or genotyping of TBNA samples obtained by convex probe EBUS has long been considered to be limited by the lack of tissue architecture in these small tissue samples. The performance of small tissue samples in NSCLC subtyping has been proven to be accurate in modern pathology practice adopting cell blocks and immunohistochemistry (IHC), reducing the NSCLC not otherwise specified rate for needle aspiration samples to $8-23 \%$ [11-13]. In addition, IHC has a proven value in improving interobserver agreement in NSCLC subtyping ( $\kappa=0.28$ for haematoxylin and eosin, and $\kappa=0.56$ for IHC) or degree of pathologist confidence [14]. Another common concern is the suitability of DNA from small needle aspiration samples for mutation analysis. Its suitability for epidermal growth factor receptor mutation analysis not only relies on adequacy in terms of the number and percentage of tumour cells but even more on the quantity and quality of the extracted DNA and the method used for mutation analysis. It is unclear what percentage and absolute number of tumour cells need to be present in a needle aspiration sample for reliable mutation testing. The minimum recommended amounts of material necessary for a good probability of providing sufficient amounts of tumour for mutational analysis is 4-8 needle aspiration passes per cell block [15-17]. A large amount of extracted DNA increases the chance of a positive test outcome and below $200 \mathrm{ng}$ of DNA the chance of an inadequate test due to sequencing artefacts is higher [18]. In general, needle aspirations generate smaller amounts of DNA compared to bronchial biopsies, but they result in an equally high success rate for mutation testing [19]. DNA extracted from formalin-fixed, paraffin-embedded small bronchial biopsies (10 unstained slides, $4 \mu \mathrm{m}$ thick) yielded on average 1690 ng (range 250-3600 ng) of DNA, while DNA extracted from needle aspirations generated smaller amounts of DNA (average $230 \mathrm{ng}$; range 120-400 ng) [19]. Very similar amounts were obtained by VAN EIJK et al. [20] (EBUS-TBNA, $n=43$ patients), average yields were $282 \mathrm{ng}$ and $280 \mathrm{ng}$ DNA from cytological smears and cell blocks, respectively. However, it has been observed that the rate of reliable mutation testing is higher if cell blocks are available (90-95\%) compared to smear alone $(70-77 \%)[13,21-23]$. In addition, multi-testing (e.g. 13 assays) has been proven feasible in $>90 \%$ of needle aspiration samples [20].

A radial endobronchial ultrasonic miniprobe (rEBUS-MP) employs a flexible catheter housing and a mechanically rotating $(400 \mathrm{rpm})$ ultrasound transducer which produces a radial $\left(360^{\circ}\right)$ ultrasound image (fig. 1). The miniaturised highresolution $20 \mathrm{MHz}$ ultrasonic probe when equipped with a balloon at the tip can be brought through the working channel of a 2.8 - $\mathrm{mm}$ bronchoscope, providing a $360^{\circ}$ view of the central airway wall once the balloon is filled with water and insufflated until airway wall contact is obtained. Using a 20$\mathrm{MHz}$ ultrasonic probe, the bronchial and tracheal wall structure can be imaged as six distinct layers [24]. The cartilage layer is always easily identified and serves as a reference to evaluate the invasiveness of either radio-occult early stage lung cancer, or a centrally located lung carcinoma with potential tracheal invasion [25-28]. Alternatively, the rEBUSMP without balloon sheath can be introduced through the 2.0$\mathrm{mm}$ biopsy channel of a standard bronchoscope and passed into the bronchial subsegments to visualise the sixth- to eighthgeneration bronchi where a characteristic ultrasound signal indicating either normal lung tissue ("snow-storm" pattern) or a peripheral pulmonary lesion can be demonstrated (fig. 2). As such, the rEBUS-MP can guide the sampling of more peripheral pulmonary lesions and increase the diagnostic yield of transbronchial lung biopsies (TBLB), even without fluoroscopic guidance.

\section{RADIAL PROBE EBUS FOR PRIMARY TUMOUR STAGING (T-FACTOR)}

The ability of the rEBUS-MP to clearly define the central airways bronchial or tracheal wall layers and adjacent anatomic structures makes it an excellent technique for Tfactor staging. Radio-occult lesions which invade through the cartilage are staged clinical stage T1a and should be treated with surgery or external radiotherapy (fig. 3). Radio-occult 

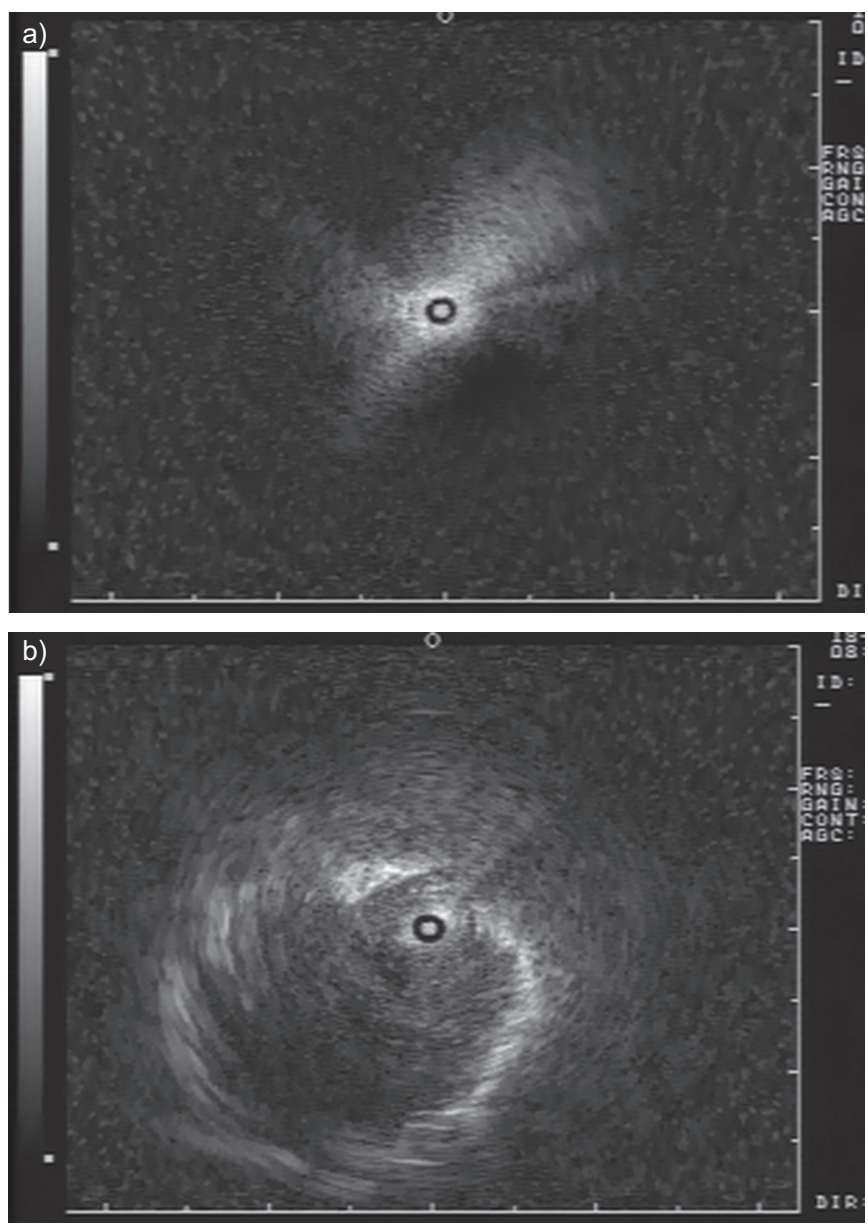

FIGURE 2. The radial endobronchial ultrasound miniprobe can visualise a) normal lung parenchyma ("snow-storm" pattern) or b) solid peripheral pulmonary lesion.

lesions which have not invaded the cartilage layer can be treated endoscopically, or by high-dose rate brachytherapy, or surgery depending on staging by additional white light and autofluorescence bronchoscopy assessing superficial appearance and dimensions (fig. 4). A frequent problem in staging the extent of a lung carcinoma located centrally adjacent to the trachea is the question of whether compression only (clinical T2a-T3 depending on tumour size) or invasion (clinical T4) is present. A rEBUS-MP has an accuracy of $93-98 \%$ to answer this question [26-28]. In a prospective study, endobronchial ultrasonography has been proven superior to computed tomography of the chest with a negative predictive value of $89 \%$ versus $42 \%$, and positive predictive value of $100 \%$ versus $51 \%$, respectively [28]

\section{CONVEX PROBE EBUS FOR MEDIASTINAL NODAL STAGING (N-FACTOR)}

Staging of lung cancer is important to assess the extent of disease and to define the best therapeutic strategy. It also has prognostic implications and allows the comparison of studies. When there are no distant metastases, mediastinal nodal involvement becomes the first prognostic factor and has major therapeutic implications. As an example, mediastinal staging before surgical resection of lung cancer is of paramount importance to limit the number of futile thoracotomies. In particular, patients with N2 mediastinal lymph node involvement remain poor candidates for initial surgical resection even if neoplastic invasion is limited to a single mediastinal station [29]. In the noninvasive assessment of mediastinal lymph nodes, positron emission tomography (PET) with F18-fluorodeoxyglucose is more accurate than computed tomography (CT) scan alone [30] and also provides significant additional information in the search for distant metastasis [31] Nevertheless, mediastinal lymph nodes positive on CT (short axis $\geqslant 10 \mathrm{~mm}$ ) or PET (visually increased uptake as compared with background) require histological confirmation because of their suboptimal specificity [30]. There are additional conditions where invasive staging also seems mandatory despite a normal mediastinum on PET or CT because the prevalence of N2/N3 disease remains significant. These conditions include central tumours, PET hilar N1 disease, or low fluorodeoxyglucose uptake in the primary tumour [32]. Until recently, mediastinoscopy was considered the "gold standard" for invasive staging of the mediastinum [33]. However, this procedure has a mortality rate of $0.2 \%$, a morbidity rate of $0.5-2.5 \%$ and requires general anaesthesia; in addition, even if it can be performed on an ambulatory basis, many patients still stay in hospital for at least one night [34].

The predominant role of mediastinoscopy has been challenged, firstly by oesophageal ultrasonography and since 2004 by endobronchial ultrasonography using a convex probe [35]. Indeed, the endoscopic echo-probe allows the exploration of the same lymph node stations as the mediastinoscope (table 1 and fig. 5). It must be stressed, that EBUS-TBNA cannot access the prevascular nodes (station 3a), the subaortic and paraaortic nodes (stations 5 and 6) or the para-oesophageal and pulmonary ligament nodes (stations 8 and 9). Some of these nodes (stations 8 and 9) can, however, be reached using oesophageal endoscopic ultrasound (EUS) with fine needle aspiration (EUS-FNA) illustrating the fact that oesophageal ultrasound is complementary to endobronchial examination rather than exclusive (table 1). Some authors have also extended the use of the EBUS scope to oesophageal exploration with sampling of stations 8 and 9 [37, 38]. Since its introduction, EBUS-TBNA has been used in multiple studies of unselected populations with lung cancer [39] or populations selected on the basis of positive CT or PET findings [40], or positive CT findings only [41], or PET findings only [8], or even normal CT and PET findings [42]. All these studies share one common characteristic: high sensitivity, specificity and diagnostic accuracy of EBUS-TBNA in staging mediastinal lymph nodes in patients with lung cancer that seems largely independent of the population selection criteria.

Several systematic reviews and meta-analysis [5, 6, 43, 44] have confirmed the high performance of EBUS-TBNA in the staging of lung cancer with pooled sensitivities of 0.93 [5], 0.88 [44] and 0.92 [6]. The suboptimal negative predicted value, however, suggests that negative findings should be confirmed by more invasive staging procedures, including mediastinoscopy, in particular when the prevalence of lymph node malignancy is high as suggested by increased lymph node size on CT or metabolic activity on PET. This is illustrated by data from the largest multicentre prospective study in which 502 patients with CT enlarged lymph nodes (mean diameter $1.6 \mathrm{~cm}$ ) were investigated with EBUS-TBNA. The sensitivity for lymph node 

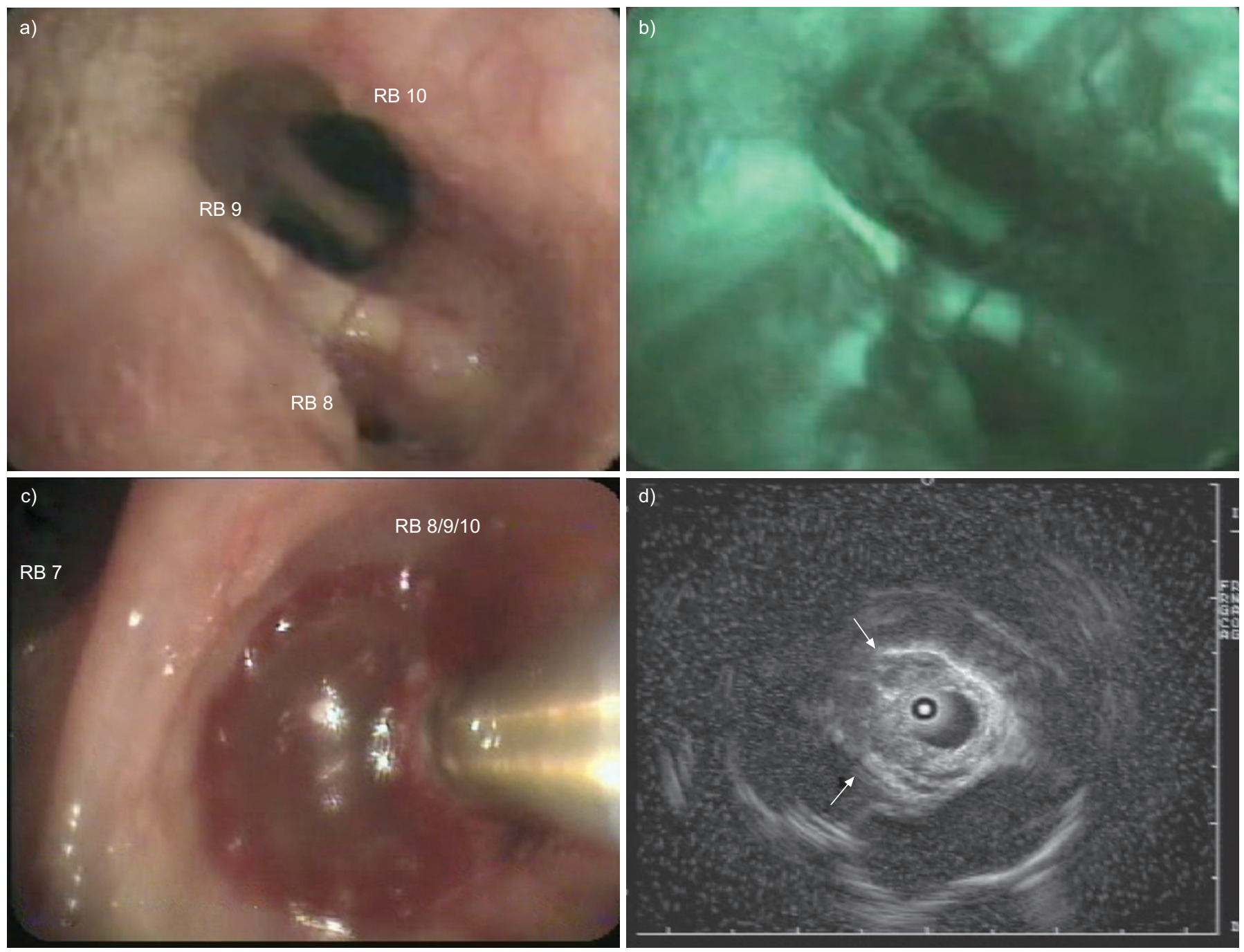

FIGURE 3. a) White light and b) autofluorescence bronchoscopy of an early stage radio-occult squamous cell carcinoma, which has been proven invasive by radial endobronchial ultrasound miniprobe with filled balloon sheath (c and d). The ultrasound image (d) illustrates interruption of white "cartilage" line, as indicated by the arrows RB: right bronchus.

metastasis detection was $94 \%$ but the negative predictive value was only $11 \%$ [41]. In a large retrospective review of 494 patients who underwent EBUS-TBNA, 29 patients with suspected or confirmed lung cancer and high suspicion of lymph node metastasis, based on CT or PET findings, had a negative EBUSTBNA and underwent subsequent mediastinoscopy. This latter procedure confirmed N2 mediastinal nodal metastases in eight $(28 \%)$ patients such that the patient-specific negative predictive value of EBUS-TBNA only amounted to $72 \%$ [45]. All these studies also demonstrated that the use of endosonographic staging avoids more invasive surgical staging in $>50 \%$ of the patients with resectable stage I-III lung cancer.

EBUS-TBNA is also a safe procedure [43], but with the rapidly increasing number of procedures it is not surprising to read occasional reports of serious complications, such as pneumothorax requiring chest tube drainage [8], infection of bronchogenic cyst [46], empyema, lung and/or mediastinal abscess [47, 48], haemopneumomediastinum [49] and even death [13].
Due to its high diagnostic accuracy, guidelines recommend EBUS-TBNA as a minimally invasive alternative to surgical staging $[32,50]$ and recent studies $[51,52]$ have compared the diagnostic accuracy of EBUS-TBNA versus invasive surgical staging techniques that are still considered the "gold standard". ANNEMA et al. [51] compared surgical staging alone versus combined endosonographic staging (EBUS-TBNA and EUSFNA) followed by surgical staging in the case of negative results, since guidelines at the time the study was designed advocated confirmation of negative endosonographic findings by mediastinoscopy $[32,50]$. If required, video-assisted thoracoscopy or left parasternal mediastinotomy could be performed in addition to mediastinoscopy. 118 patients were randomised to surgical staging and 123 to endosonography, of whom 65 also underwent surgical staging. Lymph node metastases were found in $41(35 \%)$ patients by surgical staging versus $56(46 \%)$ patients using combined EBUS and EUS $(p=0.11)$ and in 62 $(50 \%)$ patients by endosonography followed by surgical staging $(\mathrm{p}=0.02)$. The corresponding sensitivities were 0.79 versus 0.85 

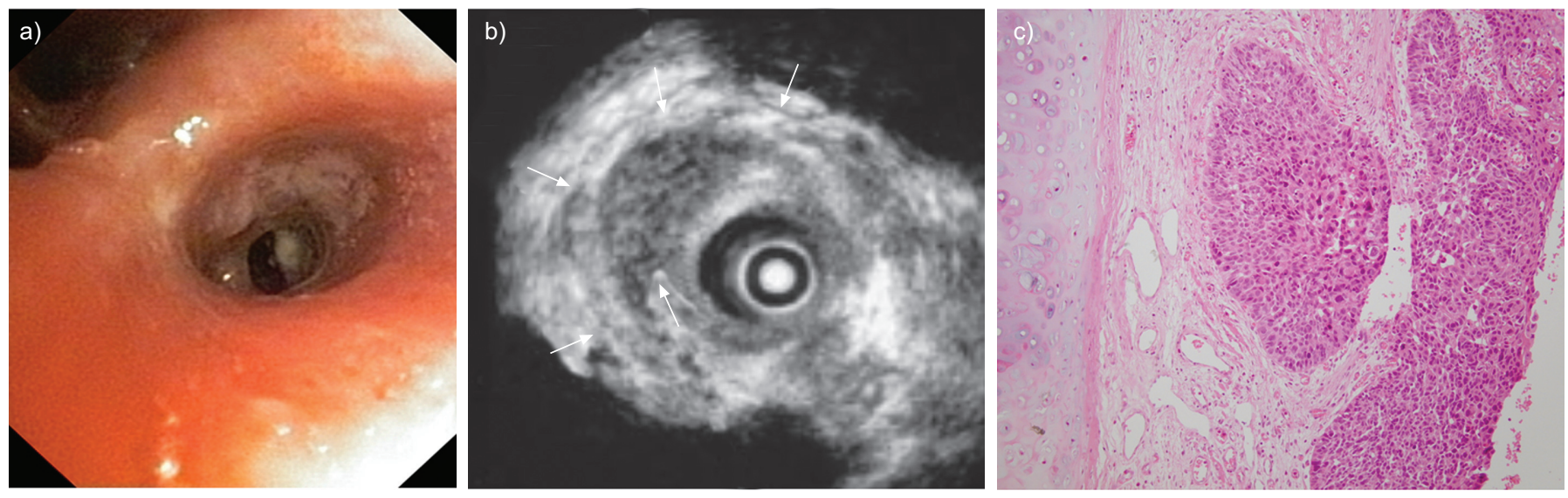

FIGURE 4. a) White light bronchoscopy of an early stage radio-occult squamous cell carcinoma, which has been proven micro-invasive by radial endobronchial ultrasound miniprobe with filled balloon sheath (b), and on histopathology (c). The arrows in b) indicate the intact white "cartilage" line on the ultrasound image.

$(p=0.47)$ and $0.94 \quad(p=0.02)$. The authors concluded that complete endosonographic evaluation followed by surgical staging in the case of negative findings had a greater sensitivity than surgical staging alone. The former strategy was also associated with a lower number of futile thoracotomies [51]. In a recent prospective study, YASUFUKU et al. [52] prospectively compared EBUS-TBNA and mediastinoscopy in 153 patients.

\begin{tabular}{|c|c|c|c|c|}
\hline \multirow[t]{2}{*}{ TABLE 1} & \multicolumn{4}{|c|}{$\begin{array}{l}\text { Accessibility to nodal stations with different } \\
\text { sampling techniques }\end{array}$} \\
\hline & & $\begin{array}{l}\text { Mediastino- } \\
\text { scopy }\end{array}$ & $\begin{array}{l}\text { EBUS- } \\
\text { TBNA }\end{array}$ & $\begin{array}{l}\text { EUS- } \\
\text { FNA }\end{array}$ \\
\hline \multicolumn{5}{|c|}{ Supraclavicular zone } \\
\hline 1 & & \pm & -- & - \\
\hline \multicolumn{5}{|c|}{$\begin{array}{l}\text { Superior mediastinal } \\
\text { nodes }\end{array}$} \\
\hline $2 R$ & & + & + & - \\
\hline $2 \mathrm{~L}$ & & + & + & + \\
\hline $4 \mathrm{R}$ & & + & + & - \\
\hline $4 \mathrm{~L}$ & & + & + & + \\
\hline 3a & & - & - & - \\
\hline $3 p$ & & - & $\pm^{\#}$ & $\pm^{\#}$ \\
\hline \multicolumn{5}{|l|}{ Aortic nodes } \\
\hline 5 & & - & - & $-^{\#}$ \\
\hline 6 & & - & - & $-\#$ \\
\hline \multicolumn{5}{|c|}{$\begin{array}{l}\text { Inferior mediastinal } \\
\text { nodes }\end{array}$} \\
\hline 7 & & + & + & + \\
\hline 8 & & - & - & + \\
\hline 9 & & - & - & + \\
\hline \multicolumn{5}{|l|}{ N1 nodes } \\
\hline 10 Hilar & & \pm & + & $\pm^{\#}$ \\
\hline 11 Interlobar & & - & + & - \\
\hline 12 Lobar & & - & + & - \\
\hline
\end{tabular}

EBUS-TBNA: endobronchial ultrasound-transbronchial needle aspiration; EUSFNA: endoscopic ultrasound-fine needle aspiration. +: accessible; -: inaccessible; \pm : may be accessible. ${ }^{\#}$ : casuistic reports that it is feasible.
They all had an endosonographic examination followed by mediastinoscopy under general anaesthesia and no significant difference was found between the two procedures. Altogether, these studies [51, 52] show that the sensitivity of endosonography is similar to that of mediastinoscopy and that using endosonography as a first staging procedure followed by surgical staging in case of negative findings is superior to surgical staging. The lower complication rate associated with EBUS-TBNA is an additional argument for its use as the first invasive mediastinal staging procedure.

EBUS-TBNA has also been used to restage patients after an induction treatment. In a recent study [53], 124 consecutive patients with tissue-proven stage IIIA-N2 disease who were treated with induction chemotherapy underwent mediastinal restaging by EBUS-TBNA. All of them underwent thoracotomy. Among the 35 patients with negative EBUS-TBNA, 28 were found to have residual stage IIIA-N2 disease at thoracotomy, such that the negative predictive value only amounted to 0.20 . A quite low negative predictive value of EBUS-TBNA was also observed when confirmation was obtained by transcervical extended bilateral mediastinal lymphadenectomy [54]: the negative predictive value of EBUS-TBNA procedure was $78 \%$. These results stress the point that negative EBUS-TBNA results after an induction treatment should be confirmed by a surgical invasive procedure. One alternative proposal, which needs validation, should be to rely on EBUS-TBNA for the initial staging and on invasive surgical staging for restaging [8].

\section{RADIAL PROBE EBUS FOR DIAGNOSIS OF PERIPHERAL PULMONARY LESIONS}

TBLB can be useful in diagnosing neoplasia, infections and certain interstitial lung diseases. The likelihood of successful sampling and diagnosis depends on whether we are dealing with focal (including local infiltrate, nodule, masses) or diffuse radiological abnormalities. A systematic review on routine flexible bronchoscopy with TBLB reported a variable (34-63\%) diagnostic yield in endobronchially invisible peripheral pulmonary lesions (PPLs) [55]. In a recent large prospective study on patients with such invisible PPLs the sensitivity of TBLB was $45 \%$ [56]. The suboptimal diagnostic yield of routine TBLB is related to the fact that endobronchially invisible PPLs are 


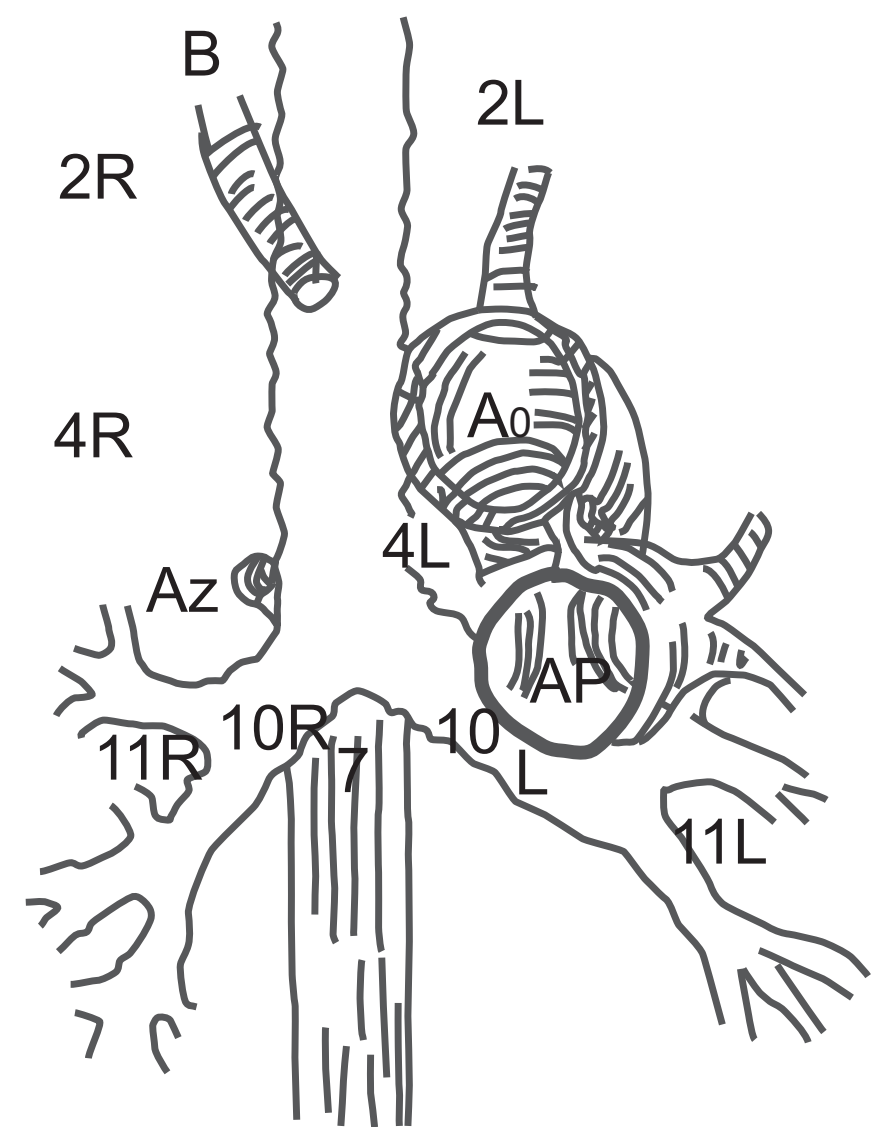

FIGURE 5. Schematic representation of the mediastinum and nodal stations that are accessible to EBUS. Ao: aorta; AP: pulmonary artery; Az: azygos vein; B: brachiocephalic artery; L: left; R: right. For precise borders of the nodal stations see [36].

often difficult to localise without any guidance technique. Indeed, their diagnostic yield mainly depends on lesion size, the proximity to the bronchial tree and the prevalence of cancer. CT-guided percutaneous transthoracic fine-needle aspiration biopsy is often considered the gold standard for PPLs, as it has a diagnostic yield of up to $90 \%$.

Traditionally, the diagnostic yield of TBLB during routine flexible bronchoscopy can be improved with the auxiliary use of radiographic fluoroscopic guidance, but even then lesions $<20 \mathrm{~mm}$ in diameter remain hard to detect. Bronchoscopic guidance techniques have evolved in recent years and might have a significant impact on the detection rate of PPLs and the diagnostic yield of TBLB. Typical examples are ultrathin bronchoscopy, conventional flexible bronchoscopy combined with rEBUS-MP, and CT-assisted electromagnetic navigation bronchoscopy with extended working channel.

The first prospective randomised trial comparing conventional TBLB to rEBUS-MP guided TBLB reported a diagnostic yield of $55 \%$ versus $79 \%(p=0.004)$, respectively [57]. Recently, two meta-analyses (literature searches through to December 2009 and through to October 2010, respectively) showed that the diagnostic yield of rEBUS-MP guided bronchoscopy was 73\% (95\% CI 70-76\%) and 71\% (95\% CI 67-76\%), respectively [58, 59]. A significant relationship between the prevalence of malignancy and study sensitivity was demonstrated [58].
Across several studies, the rEBUS-MP detection or visualisation yield was $10-20 \%$ higher than the diagnostic yield after TBLB [60]. The procedural feature that might explain this observation is the effect of probe position in relation to the lesion: sometimes rEBUS-MP can only visualise the lesion from a bronchus adjacent to the lesion. Differences in the technique of rEBUS-MP guided TBLB with respect to tools, such as fluoroscopy, guide sheath and distance measurement, were not considered of influence in the differences between detection and diagnostic yield. Indeed, the only procedural feature consistently associated with improved diagnostic yield is the ability to locate the rEBUS-MP within the pulmonary lesion, as compared to a positioning of the rEBUS-MP in a bronchus adjacent to the target lesion [61, 62]. An improvement in the diagnostic yield for lesions only detected adjacent to the airway with rEBUS-MP has been reported by performance of a conventional TBNA in these lesions instead of a TBLB [63].

Several clinical, radiological and operational factors have been evaluated that might predict PPLs visibility by rEBUS-MP prior to the procedure, and thus might justify the choice of a rEBUS-MP procedure. Pooled statistics demonstrated a significantly $(\mathrm{p}=0.007)$ higher diagnostic yield of $78 \%(95 \%$ CI $73-$ $82 \%$ ) for lesions $>20 \mathrm{~mm}$ compared to $56 \%$ (95\% CI 51\%-61\%) for lesions $\leqslant 20 \mathrm{~mm}$ [58]. The distance from hilum to lesion was found to significantly affect EBUS-MP detection rate [60]. As such, a distance of $\leqslant 50 \mathrm{~mm}$ between the hilum and the peripheral pulmonary lesion was found to have a significantly higher detection rate of $91 \%$ compared to a $66 \%$ detection rate for PPLs located $>50 \mathrm{~mm}$ from the hilum ( $p=0.0001)$ [60]. It is clear that the diagnostic yield of bronchoscopy with rEBUS-MP guidance is only valuable if the operator has expertise in this newer technique. A randomised controlled trial comparing conventional TBLB to rEBUS-MP guided TBLB performed by bronchoscopists at all levels of expertise reported an overall diagnostic yield of $40 \%$ versus $31 \%(p=0.29)$, respectively [64].

A consistent finding is that rEBUS-MP guided TBLB has a high safety profile. The $1 \%$ pneumothorax rate and $0.4 \%$ chest tube rate with rEBUS-MP guided TBLB is significantly lower when compared with a $25 \%$ pneumothorax rate and an overall $5 \%$ chest tube rate for CT-guided transthoracic needle aspiration or biopsies [58, 65].

Despite the lack of well-designed multicentre, randomised controlled trials, the diagnostic value of rEBUS-MP is considered non-inferior to other techniques, such as fluoroscopically guided TBLB, ultrathin bronchoscopy, CT-guided transthoracic needle biopsy, and electromagnetic navigation (EMN) bronchoscopy, certainly when its safety profile is taken into account. An uncontrolled small feasibility study comparing rEBUS-MP guided TBLB to fluoroscopy-guided TBLB reported a similar diagnostic yield of $80 \%$ versus $76 \%$, respectively, without radiation exposure for the rEBUS-MP technique [66]. A prematurely closed non-inferiority randomised controlled trial comparing rRBUS-MP guided TBLB and ultrathin bronchoscopy (scope with a $3.4 \mathrm{~mm}$ distal end and $1.7 \mathrm{~mm}$ working channel) reported a diagnostic yield of $62 \%$ versus $65 \%$, respectively, but the complication rate was slightly higher for ultrathin bronchoscopy ( $2 \%$ versus $5 \%, p=0.28)$ [67]. A small prospective randomised pragmatic trial comparing rEBUS-MP guided TBLB to CT-guided percutaneous needle 
biopsy reported a sensitivity of $86 \%$ versus $92 \%(p=1.00)$, respectively, but the complication rate was significantly higher in CT-guided percutaneous needle biopsy ( $3 \%$ versus $27 \%$, $\mathrm{p}=0.03$ ) [68]. A prospective trial comparing three modalities concluded that the diagnostic yield of the combined rEBUS-MP and EMN bronchoscopy (88\%) was greater than the yield of rEBUS-MP alone $(69 \%)$ or ENB alone $(59 \%$; $p=0.02)$ [69].

\section{CONVEX EBUS PROBE FOR THE DIAGNOSIS OF CENTRAL PARENCHYMAL LUNG CANCERS}

Some central lung cancers are in close contact with the major airways but diagnosis cannot be reached using conventional bronchoscopy. In a recent retrospective study of 60 patients [70], EBUS-TBNA had a sensitivity of $82 \%$ and allowed avoidance of transthoracic needle aspiration or an invasive surgical procedure in $47 \%$ and $30 \%$ of the patients, respectively. However, negative results should be confirmed owing to the suboptimal negative predictive value.

\section{CONCLUSIONS}

EBUS has clearly strengthened the central role of bronchoscopy in the diagnosis and staging of lung cancer. Its safety together with convincing results in different presentations, including accurate delineation of tumour invasion, pathological and molecular diagnosis of central and peripheral tumours, and lymph node staging of the mediastinum, explain its rapidly growing use.

\section{STATEMENT OF INTEREST}

Conflict of interest information can be found alongside the online version of this article at err.ersjournals.com

\section{REFERENCES}

1 Fujiwara T, Yasufuku K, Nakajima T, et al. The utility of sonographic features during endobronchial ultrasound-guided transbronchial needle aspiration for lymph node staging in patients with lung cancer: a standard endobronchial ultrasound image classification system. Chest 2010; 138: 641-647.

2 Memoli JS, El-Bayoumi E, Pastis NJ, et al. Using endobronchial ultrasound features to predict lymph node metastasis in patients with lung cancer. Chest 2011; 140: 1550-1556.

3 Lee HS, Lee GK, Lee HS, et al. Real-time endobronchial ultrasound-guided transbronchial needle aspiration in mediastinal staging of non-small cell lung cancer: how many aspirations per target lymph node station? Chest 2008; 134: 368-374.

4 Block MI. Endobronchial ultrasound for lung cancer staging: how many stations should be sampled? Ann Thorac Surg 2010; 89: 1582-1587.

5 Gu P, Zhao YZ, Jiang LY, et al. Endobronchial ultrasound-guided transbronchial needle aspiration for staging of lung cancer: a systematic review and meta-analysis. Eur J Cancer 2009; 45: 1389-1396.

6 Chandra S, Nehra M, Agarwal D, et al. Diagnostic accuracy of endobronchial ultrasound-guided transbronchial needle biopsy in mediastinal lymphadenopathy: a systematic review and metaanalysis. Respir Care 2012; 57: 384-391.

7 Thunnissen E, Kerr KM, Herth FJ, et al. The challenge of NSCLC diagnosis and predictive analysis on small samples. Practical approach of a working group. Lung Cancer 2012; 76: 1-18.

8 Bauwens O, Dusart M, Pierard P, et al. Endobronchial ultrasound and value of PET for prediction of pathological results of mediastinal hot spots in lung cancer patients. Lung Cancer 2008; 61: 356-361.
9 Nakajima T, Yasufuku K, Takahashi R, et al. Comparison of 21gauge and 22-gauge aspiration needle during endobronchial ultrasound-guided transbronchial needle aspiration. Respirology 2011; 16: 90-94.

10 Herth FJ, Schuler H, Gompelmann D, et al. Endobronchial ultrasound-guided lymph node biopsy with transbronchial needle forceps: a pilot study. Eur Respir J 2012; 39: 373-377.

11 Nicholson AG, Gonzalez D, Shah P, et al. Refining the diagnosis and EGFR status of non-small cell lung carcinoma in biopsy and cytologic material, using a panel of mucin staining, TTF-1, cytokeratin 5/6, and P63, and EGFR mutation analysis. J Thorac Oncol 2010; 5: 436-441.

12 Tournoy K, Caprieaux M, Deschepper E, et al. Are EUS-FNA and EBUS-TBNA specimens reliable for subtyping non-small cell lung cancer? Lung Cancer 2012; 76: 46-50.

13 Navani N, Brown JM, Nankivell M, et al. Suitability of endobronchial ultrasound-guided transbronchial needle aspiration specimens for subtyping and genotyping of non-small cell lung cancer: a multicenter study of 774 patients. Am J Respir Crit Care Med 2012; 185: 1316-1322.

14 Steinfort DP, Russell PA, Tsui A, et al. Interobserver agreement in determining non-small cell lung cancer subtype in specimens acquired by EBUS-TBNA. Eur Respir J 2012; 40: 699-705.

15 Pirker R, Herth FJ, Kerr KM, et al. Consensus for EGFR mutation testing in non-small cell lung cancer: results from a European workshop. J Thorac Oncol 2010; 5: 1706-1713.

16 Muley T, Herth FJF, Schnabel P, et al. From tissue to molecular phenotyping: pre-analytical requirements Heidelberg experience. Transl Lung Cancer Res 2012; 1: 111-121.

17 Gately K, O'Flaherty J, Cappuzzo F, et al. The role of the molecular footprint of EGFR in tailoring treatment decisions in NSCLC. J Clin Pathol 2012; 65: 1-7.

18 Williams C, Pontén F, Moberg C, et al. A high frequency of sequence alterations is due to formalin fixation of archival specimens. Am J Pathol 1999; 155: 1467-1471.

19 Arcila ME, Oxnard GR, Nafa K, et al. Rebiopsy of lung cancer patients with acquired resistance to EGFR inhibitors and enhanced detection of the T790M mutation using a locked nucleic acid-based assay. Clin Cancer Res 2011; 17: 1169-1180.

20 van Eijk R, Licht J, Schrumpf M, et al. Rapid KRAS, EGFR, BRAF and PIK3CA mutation analysis of fine needle aspirates from nonsmall-cell lung cancer using allele-specific qPCR. PLoS One 2011; 6: e17791.

21 Nakajima T, Yasufuku K, Suzuki M, et al. Assessment of epidermal growth factor receptor mutation by endobronchial ultrasoundguided transbronchial needle aspiration. Chest 2007; 132: 597-602.

22 Garcia-Olivé I, Monsé E, Andreo F, et al. Endobronchial ultrasound-guided transbronchial needle aspiration for identifying EGFR mutations. Eur Respir J 2010; 35: 391-395.

23 Schuurbiers OC, Looijen-Salamon MG, Ligtenberg MJ, et al. A brief retrospective report on the feasibility of epidermal growth factor receptor and KRAS mutation analysis in transesophageal ultrasound- and endobronchial ultrasound-guided fine needle cytological aspirates. J Thorac Oncol 2010; 5: 1664-1667.

24 Baba M, Sekine Y, Suzuki M, et al. Correlation between endobronchial ultrasonography images and histologic findings in normal and tumor-invaded bronchial wall. Lung Cancer 2002; 35: 65-71.

25 Miyazu Y, Miyazawa T, Kurimoto N, et al. Endobronchial ultrasonography in the assessment of centrally located early-stage lung cancer before photodynamic therapy. Am J Respir Crit Care Med 2002; 165: 832-837.

26 Kurimoto N, Murayama M, Yoshioka T, et al. Assessment of usefulness of endobronchial ultrasonography in determination of depth of tracheobronchial tumor invasion. Chest 1999; 115: 1500-1506. 
27 Tanaka F, Muro K, Yamasaki S, et al. Evaluation of tracheabronchial wall invasion using transbronchial ultrasonography (TBUS). Eur J Cardiothorac Surg 2000; 17: 570-574.

28 Herth F, Ernst A, Schulz M, et al. Endobronchial ultrasound reliably differentiates between airway infiltration and compression by tumor. Chest 2003; 123: 458-462.

29 Ohta Y, Shimizu Y, Minato H, et al. Results of initial operations in non-small cell lung cancer patients with single-level N2 disease. Ann Thorac Surg 2006; 81: 427-433.

30 Gould MK, Kuschner WG, Rydzak CE, et al. Test performance of positron emission tomography and computed tomography for mediastinal staging in patients with non-small-cell lung cancer: a meta-analysis. Ann Intern Med 2003; 139: 879-892.

31 Fischer B, Lassen U, Mortensen J, et al. Preoperative staging of lung cancer with combined PET-CT. N Engl J Med 2009; 361: 32-39.

32 De Leyn P, Lardinois D, Van Schil PE, et al. ESTS guidelines for preoperative lymph node staging for non-small cell lung cancer. Eur J Cardiothorac Surg 2007; 32: 1-8.

33 Toloza EM, Harpole L, Detterbeck F, et al. Invasive staging of nonsmall cell lung cancer: a review of the current evidence. Chest 2003; 123: Suppl. 1, 157S-166S.

34 Luke WP, Pearson FG, Todd TR, et al. Prospective evaluation of mediastinoscopy for assessment of carcinoma of the lung. J Thorac Cardiovasc Surg 1986; 91: 53-56.

35 Yasufuku K, Chiyo M, Sekine Y, et al. Real-time endobronchial ultrasound-guided transbronchial needle aspiration of mediastinal and hilar lymph nodes. Chest 2004; 126: 122-128.

36 Rusch VW, Asamura $\mathrm{H}$, Watanabe $\mathrm{H}$, et al. The IASLC lung cancer staging project: a proposal for a new international lymph node map in the forthcoming seventh edition of the TNM classification for lung cancer. J Thorac Oncol 2009; 4: 568-577.

37 Herth FJ, Krasnik M, Kahn N, et al. Combined endoscopicendobronchial ultrasound-guided fine-needle aspiration of mediastinal lymph nodes through a single bronchoscope in 150 patients with suspected lung cancer. Chest 2010; 138: 790-794.

38 Hwangbo B, Lee GK, Lee HS, et al. Transbronchial and transesophageal fine-needle aspiration using an ultrasound bronchoscope in mediastinal staging of potentially operable lung cancer. Chest 2010; 138: 795-802.

39 Wallace MB, Pascual JM, Raimondo M, et al. Minimally invasive endoscopic staging of suspected lung cancer. JAMA 2008; 299: 540-546.

40 Vincent BD, El-Bayoumi E, Hoffman B, et al. Real-time endobronchial ultrasound-guided transbronchial lymph node aspiration. Ann Thorac Surg 2008; 85: 224-230.

41 Herth FJ, Eberhardt R, Vilmann P, et al. Real-time endobronchial ultrasound guided transbronchial needle aspiration for sampling mediastinal lymph nodes. Thorax 2006; 61: 795-798.

42 Herth FJ, Ernst A, Eberhardt R, et al. Endobronchial ultrasoundguided transbronchial needle aspiration of lymph nodes in the radiologically normal mediastinum. Eur Respir J 2006; 28: 910-914.

43 Varela-Lema L, Fernández-Villar A, Ruano-Ravina A. Effectiveness and safety of endobronchial ultrasound-transbronchial needle aspiration: a systematic review. Eur Respir J 2009; 33: 1156-1164.

44 Adams K, Shah PL, Edmonds L, et al. Test performance of endobronchial ultrasound and transbronchial needle aspiration biopsy for mediastinal staging in patients with lung cancer: systematic review and meta-analysis. Thorax 2009; 64: 757-762.

45 Defranchi SA, Edell ES, Daniels CE, et al. Mediastinoscopy in patients with lung cancer and negative endobronchial ultrasound guided needle aspiration. Ann Thorac Surg 2010; 90: 1753-1757.

46 Anantham D, Phua GC, Low SY, et al. Role of endobronchial ultrasound in the diagnosis of bronchogenic cysts. Diagn Ther Endosc 2011; 2011: 468237.
47 Huang CT, Chen CY, Ho CC, et al. A rare constellation of empyema, lung abscess, and mediastinal abscess as a complication of endobronchial ultrasound-guided transbronchial needle aspiration. Eur J Cardiothorac Surg 2011; 40: 264-265.

48 Moffatt-Bruce SD, Ross P Jr. Mediastinal abscess after endobronchial ultrasound with transbronchial needle aspiration: a case report. J Cardiothorac Surg 2010; 5: 33.

49 Botana-Rial M, Núñez-Delgado M, Pallarés-Sanmartín A, et al. Intramural hematoma of the pulmonary artery and hemopneumomediastinum after endobronchial ultrasound-guided transbronchial needle aspiration. Respiration 2012; 83: 353-356.

50 Detterbeck FC, Jantz MA, Wallace M, et al. Invasive mediastinal staging of lung cancer: ACCP evidence-based clinical practice guidelines (2nd edition). Chest 2007; 132: Suppl. 3, 202S-220S.

51 Annema JT, van Meerbeeck JP, Rintoul RC, et al. Mediastinoscopy vs endosonography for mediastinal nodal staging of lung cancer: a randomized trial. JAMA 2010; 304: 2245-2252.

52 Yasufuku K, Pierre A, Darling G, et al. A prospective controlled trial of endobronchial ultrasound-guided transbronchial needle aspiration compared with mediastinoscopy for mediastinal lymph node staging of lung cancer. J Thorac Cardiovasc Surg 2011; 142: 1393-1400.

53 Herth FJ, Annema JT, Eberhardt R, et al. Endobronchial ultrasound with transbronchial needle aspiration for restaging the mediastinum in lung cancer. J Clin Oncol 2008; 26: 3346-3350.

54 Szlubowski A, Herth FJ, Soja J, et al. Endobronchial ultrasoundguided needle aspiration in non-small-cell lung cancer restaging verified by the transcervical bilateral extended mediastinal lymphadenectomy - a prospective study. Eur J Cardiothorac Surg 2010; 37: 1180-1184.

55 Rivera MP, Mehta AC, American College of Chest Physicians. Initial diagnosis of lung cancer: ACCP evidence-based clinical practice guidelines (2nd edition). Chest 2007; 132: Suppl. 3, 131S-148S.

56 Trisolini R, Cancellieri A, Tinelli C, et al. Performance characteristics and predictors of yield from transbronchial needle aspiration in the diagnosis of peripheral pulmonary lesions. Respirology 2011; 16: 1144-1149.

57 Paone G, Nicastri E, Lucantoni G, et al. Endobronchial ultrasounddriven biopsy in the diagnosis of peripheral lung lesions. Chest 2005; 128: 3551-3557.

58 Steinfort DP, Khor YH, Manser RL, et al. Radial probe endobronchial ultrasound for the diagnosis of peripheral lung cancer: systematic review and meta-anlysis. Eur Respir J 2011; 37: 902-910.

59 Wang Memoli JS, Nietert PJ, Sivestri GA. Meta-analysis of guided bronchoscopy for the evaluation of the pulmonary nodule. Chest 2012; 142: 385-393.

60 Tay JH, Irving L, Antippa P, et al. Radial probe endobronchial ultrasound: factors influencing visualization yield of peripheral pulmonary lesions. Respirology 2013; 18: 185-190.

61 Yamada N, Yamazaki K, Kurimoto N, et al. Factors related to diagnostic yield of transbronchial biopsy using endobronchial ultrasonography with guide sheath in small peripheral pulmonary lesions. Chest 2007; 132: 603-608.

62 Huang CT, Ho CC, Tsai YJ, et al. Factors influencing visibility and diagnostic yield of transbronchial biopsy using endobronchial ultrasound in peripheral pulmonary lesions. Respirology 2009; 14: 859-864.

63 Chao TY, Chien MT, Lie CH, et al. Endobronchial ultrasonographyguided transbronchial needle aspiration increases the diagnostic yield of peripheral pulmonary lesions: a randomized trial. Chest 2009; 136: 229-236.

64 Roth K, Eagan TM, Andreassen AH, et al. A randomised trial of endobronchial ultrasound guided sampling in peripheral lung lesions. Lung Cancer 2011; 74: 219-225. 
65 Fielding DI, Robinson PJ, Kurimoto N. Biopsy site selection for endobronchial ultrasound guide-sheath transbronchial biopsy of peripheral lung lesions. Intern Med J 2008; 38: 77-84.

66 Herth FJ, Ernst A, Becker HD. Endobronchial ultrasound-guided transbronchial lung biopsy in solitary pulmonary nodules and peripheral lesions. Eur Respir J 2002; 20: 972-974.

67 Oki M, Saka H, Kitagawa C, et al. Randomized study of endobronchial ultrasound-guided transbronchial biopsy: thin bronchoscopic method versus guide sheath method. I Thorac Oncol 2012; 7: 535-541.
68 Steinfort DP, Vincent J, Heinze S, et al. Comparative effectiveness of radial probe endobronchial ultrasound versus CT-guided needle biopsy for evaluation of peripheral pulmonary lesions: a randomized pragmatic trial. Respir Med 2011; 105: 1704-1711.

69 Eberhardt R, Anantham D, Ernst A, et al. Multimodality bronchoscopic diagnosis of peripheral lung lesions: a randomised controlled trial. Am J Respir Crit Care Med 2007; 176: 36-41.

70 Tournoy KG, Rintoul RC, van Meerbeeck JP, et al. EBUS-TBNA for the diagnosis of central parenchymal lung lesions not visible at routine bronchoscopy. Lung Cancer 2009; 63: 45-49. 